\title{
Predictive Performance of Glycated Hemoglobin for Incident Diabetes Compared with Glucose Tolerance Test According to Central Obesity
}

\author{
Suji Yoo ${ }^{1}$, Jaehoon Jung ${ }^{1,2}$, Hosu Kim ${ }^{1,2}$, Kyoung Young Kim ${ }^{1,2}$, Soo Kyoung Kim²,3 Jungwha Jung, \\ Jong Ryeal Hahm ${ }^{2,3}$, Jong Ha Baek ${ }^{1,2}$ \\ ${ }^{1}$ Department of Internal Medicine, Gyeongsang National University Changwon Hospital, Gyeongsang National University \\ College of Medicine, Changwon; ${ }^{2}$ Institute of Health Science, Gyeongsang National University; ${ }^{3}$ Department of Internal \\ Medicine, Gyeongsang National University Hospital, Gyeongsang National University College of Medicine, Jinju, Korea
}

Background: To examine whether glycated hemoglobin (HbAlc) test would be a suitable screening tool for detecting high-risk subjects for diabetes compared to oral glucose tolerance test (OGTT) according to accompanied central obesity.

Methods: In this prospective population-based cohort study, both OGTT and HbAlc tests were performed and continued every 2 years up to 12 years among individuals with non-diabetic state at baseline (aged 40 to 69 years, $n=7,512$ ). Incident diabetes was established by a doctor, $\mathrm{HbA1c} \geq 6.5 \%$, and/or fasting plasma glucose (FPG) $\geq 126 \mathrm{mg} / \mathrm{dL}$, and/or 2-hour postprandial glucose (2hPG) level based on OGTT $\geq 200 \mathrm{mg} / \mathrm{dL}$. Discriminative capacities of high HbA1c ( $\geq 5.7 \%)$ versus high $2 \mathrm{hPG}$ ( $\geq 140 \mathrm{mg} / \mathrm{dL})$ for predicting incident diabetes were compared using Cox-proportional hazard regression and C-index.

Results: During the median 11.5 years of follow-up period, 1,341 (17.6\%) developed diabetes corresponding to an incidence of 22.1 per 1,000 person-years. Isolated high 2hPG was associated with higher risk for incident diabetes (hazard ratio [HR], 4.29; $95 \%$ confidence interval [CI], 3.56 to 5.17) than isolated high HbAlc (HR, 2.79; 95\% CI, 2.40 to 3.26; $P<0.05$ ). In addition, high $2 \mathrm{hPG}$ provided better discriminatory capacity than high $\mathrm{HbAlc}(\mathrm{C}$-index 0.79 vs. $0.75, P<0.05)$. Meanwhile, in subjects with central obesity, the HR (3.95 [95\% CI, 3.01 to 5.18] vs. 2.82 [95\% CI, 2.30 to 3.46]) and discriminatory capacity of incident diabetes (C-index 0.75 vs. 0.75$)$ between two subgroups became comparable.

Conclusion: Even though the overall inferior predictive capacity of HbAlc test than OGTT, HbAlc test might plays a complementary role in identifying high risk for diabetes especially in subjects with central obesity with increased sensitivity.

Keywords: Glycated hemoglobin A; Glucose tolerance test; Diabetes mellitus, type 2; Obesity, abdominal

\section{INTRODUCTION}

Prediabetes is an intermediate stage in the transition between

Received: 10 August 2020, Revised: 28 September 2020,

Accepted: 8 October 2020

Corresponding author: Jong Ha Baek

Department of Internal Medicine, Gyeongsang National University Changwon

Hospital, Gyeongsang National University College of Medicine, 11 Samjeongja-

ro, Seongsan-gu, Changwon 51472, Korea

Tel: +82-55-214-3741, Fax: +82-55-214-3741, E-mail: jongha100@gmail.com normal glucose tolerance (NGT) to overt diabetes. Prediabetes is associated with a modest increase in the risk for incident cardiovascular disease $[1,2]$ and accurate diagnosis of diabetes and

\section{Copyright $(92020$ Korean Endocrine Society}

This is an Open Access article distributed under the terms of the Creative Commons Attribution Non-Commercial License (https://creativecommons.org/ licenses/by-nc/4.0/) which permits unrestricted non-commercial use, distribution, and reproduction in any medium, provided the original work is properly cited. 
prediabetes is important to determine the survival outcomes in patients with chronic heart failure [3], or coronary artery disease [4]. Therefore, it is important to perform appropriate tests to detect high-risk subjects to prevent the progression to diabetes and related cardiometabolic outcomes. The diagnosis of diabetes or prediabetes has been traditionally based on fasting plasma glucose (FPG) and/or 2-hour postprandial glucose (2hPG) after 75-g oral glucose tolerance test (OGTT). Additionally, an International Expert Committee recommended measurement of glycated hemoglobin $(\mathrm{HbA1c})$ levels as a diagnostic parameter for diabetes (cutoff of 6.5\%) [5] and the American Diabetes Association (ADA) recommended $5.7 \%$ to $6.4 \%$ as the cutoff for prediabetes [6].

Among different glycemic diagnostic parameters, FPG was contentious in identifying high-risk subjects while impaired glucose tolerance (IGT) was suggested as a strong surrogate marker that is associated with diabetic complications and cardiovascular outcomes [7]. Additional performance of OGTT or HbA1c test can be used to detect high-risk subjects for diabetes or early type 2 diabetes mellitus (T2DM) compared with FPG test alone [8-11]. Although the overall sensitivity of $2 \mathrm{hPG}$ by OGTT is higher than HbA1c levels for the diagnosis of diabetes [12-14] or prediabetes $[15,16]$, application of OGTT in clinical practice is a huge challenge. Lack of reproducibility and requiring extensive patient preparation with multiple sampling are barriers to conducting OGTT [17]. By contrast, the advantage of using HbA1c for diagnosis of T2DM includes its stability at ambient temperature, limited biological variability, and convenience to collect single blood samples during non-fasting conditions for diagnosis and treatment. A relatively simple and reproducible HbAlc test can play a complementary role in identifying highrisk subjects for diabetes. However, the usefulness of $\mathrm{HbAlc}$ in the screening and diagnosis of diabetes has been widely debated [18-20]. In addition, a low diagnostic concordance between different diagnostic parameters in non-diabetic states shows that a single diagnostic test is not adequate to diagnose high-risk subjects in the general population [21-23].

Central obesity is the main pathophysiologic comorbidity that is related to diabetes and metabolic syndrome. A previous study showed that the concordance between HbA1c criteria and OGTT criteria for prediabetes was affected by the increased body mass index (BMI) and sensitivity of HbAlc test for prediabetes compared with OGTT increased in the obese population [24]. The correlation between BMI and HbAlc varied according to glycemic status in which BMI was significantly positively associated with $\mathrm{HbA} 1 \mathrm{c}$ in the non-diabetic but not diabetic population [25]. However, few studies compare the risk of incident diabetes based on complex glycemic parameters that simultaneously evaluated OGTT and HbAlc, and the role of obesity in determining the predictive value of each test. Therefore, it is important to identify subjects who are appropriate for each diagnostic test and their sensitivity and specificity. Thus, we compared the clinical and socioeconomic characteristics according to different glycemic parameters based on OGTT and $\mathrm{HbAlc}$ test, and evaluated the prognostic performance of each glycemic parameter (FPG, 2hPG in OGTT, HbA1c) in identifying high-risk people for incident T2DM. Further, the hazard ratio (HR) and diagnostic performance of each test was compared depending on the presence of central obesity.

\section{METHODS}

\section{Study design and population}

We collected data from the Korean Genome and Epidemiologic Study (KoGES) that is a community-based government-funded cohort study involving residents recruited from urban (Ansan) and rural (Ansung) communities. A total of 10,030 participants aged 40 to 69 years were voluntarily enrolled at baseline between 2001 and 2002, with follow-up examination every 2 years. The retention rate was $62.8 \%$ at the end of the 6 th followup phase, and $44.4 \%(n=4,452)$ of the baseline participants responded consecutively to all six follow-up phases by 2014 [26]. We excluded subjects who were previously diagnosed with diabetes $(n=675)$, who were undiagnosed but met diagnostic criteria of diabetes based on OGTT or HbA1c $(n=580)$ to include subjects with non-diabetic state. In addition, we also excluded those who had anemia (hemoglobin levels $<13.5 \mathrm{mg} / \mathrm{dL}$ [men] and $<11.5 \mathrm{mg} / \mathrm{dL}$ [women]) or hemoglobinemia (hemoglobin levels $>17.5 \mathrm{mg} / \mathrm{dL}$ [men] and $>16 \mathrm{mg} / \mathrm{dL}$ [women]) because $\mathrm{HbA1c}$ levels were affected by hemoglobinopathies or anemia and disorders associated with accelerated red cell turnover disease $(n=1,013)$ [5]. Finally, 7,512 subjects (3,536 men) were included in this study. Written informed consent by the patients was waived due to a retrospective nature of the study. This study was approved by the ethics committee of Gyeongsang National University Hospital (IRB no. 2020-03-027).

\section{Baseline variables}

The baseline survey included evaluation of demographic, socioeconomic (education level, monthly incomes, and family history of diabetes in first-degree relatives), and lifestyle factors (alcohol/smoking intake, physical activity) by trained interviewers. 
Anthropometric and clinical measurements were obtained including OGTT. After fasting for 12 hours, the glucose levels and lipid profiles were measured using a Hitachi 747 chemistry analyzer (Hitachi Ltd., Tokyo, Japan). The HbA1c level was determined by high-performance liquid chromatography (Variant II, BioRad Laboratories, Hercules, CA, USA). The circulating concentration of $\mathrm{C}$-reactive protein (CRP) was measured by immunoradiometric assay (ADVIA 1650, Bayer Diagnostics, Tarrytown, NY, USA). OGTT was performed by ingestion of standard 75 g glucose load, with glucose and insulin levels determined at 0,60 , and 120 minutes. The insulin resistance was calculated by a homeostasis model assessment of insulin resistance (HOMA-IR), using the following formula: [fasting plasma insulin $(\mu \mathrm{IU} / \mathrm{mL}) \times \mathrm{FPG}(\mathrm{mg} / \mathrm{dL}) / 405]$ [27]. The creatinine clearance was calculated using the chronic kidney disease epidemiology collaboration equation [28].

The presence of central obesity was defined by a waist circumference (WC) with the cut off values of $90 \mathrm{~cm}$ or more for men and $85 \mathrm{~cm}$ or more for women using standard methods in subjects wearing light clothes [29]. Self-reported smoking habit was classified into three categories: non-, ex-, and current smoker, and the alcohol consumption status was categorized into three groups: non-, ex-, and current intake. Monthly incomes were classified into three categories: $<\$ 1,250 /$ month, $\$ 1,250$ to $3,300 /$ month, $\geq \$ 3,300 /$ month. Physical activity was assessed in a binary fashion, and those who performed moderate intensity activity for 150 minutes or more within a week were considered to practice regular physical activity. Blood pressure was recorded three times in the morning with a relaxed state for at least 10 minutes with 5-minute rest period between the measurements. Glucose measurements were assessed in binary fashion, using the following cut points: IGT, 2hPG 140 to $199 \mathrm{mg} / \mathrm{dL}$; high $\mathrm{HbA} 1 \mathrm{c}, \mathrm{HbA} 1 \mathrm{c}$ levels $5.7 \%$ to $6.4 \%$. At baseline, subjects were categorized into four groups based on the results of OGTT and HbA1c tests: (1) NGT/normal HbA1c, (2) NGT/high HbAlc, (3) IGT/normal HbA1c, and (4) IGT/high HbAlc.

\section{Outcomes}

All subjects underwent glycemic measurements (both OGTT and $\mathrm{HbA} 1 \mathrm{c}$ ) at each biannual follow-up visit, and continued consecutively up to six follow-up phases by 2014. Among those with non-diabetic status at baseline, incident diabetes was defined if subjects were newly diagnosed with diabetes clinically or FPG was $126 \mathrm{mg} / \mathrm{dL}$ or more and/or $2 \mathrm{hPG}$ was $200 \mathrm{mg} / \mathrm{dL}$ or more, and/or HbA1c was $6.5 \%$ or more. The date of diagnosis was also recorded in this cohort study. The minimum and maxi- mum follow-up duration was 17 and 152 months, respectively.

\section{Statistical analysis}

Continuous variables are presented as mean \pm standard deviation for normally distributed variables or median with interquartile range (IQR) for non-normally distributed variables. Categorical variables are presented as counts and corresponding percentages. The baseline variables between four subgroups according to different glycemic parameters were compared using analysis of variance (ANOVA) for continuous variables and Pearson's chi-square test for categorical variables. Additionally, Tukey's honestly significant difference (HSD) post hoc analysis was used to for all pair wise comparison and Bonferroni correction method was used for categorical variables. The difference in correlation between $2 \mathrm{hPG}$ and $\mathrm{HbA} 1 \mathrm{c}$ according to the presence of central obesity was assessed using pairwise comparison with the Least Square Means. Cox proportional hazards regression analysis was performed to calculate HR and 95\% confidence interval (CI) for incident diabetes during follow-up according to the complex glycemic status at baseline using NGT with normal HbA1c level as the reference category. The potential confounding variables were adjusted for area, age, sex, estimated glomerular filtration, CRP, total-to-high density lipoprotein (HDL) cholesterol ratio, triglyceride (TG), systolic/diastolic blood pressure (SBP/DBP), and socioeconomic factors (education levels, monthly incomes, alcohol/smoking status, physical activity, family history of diabetes). The follow-up time was defined as the interval in days between the date of baseline examination and the date of last follow-up or the date of incident diabetes. Harrell concordance index (C-index) by the receiver operating characteristic (ROC) analysis was performed to assess the role of additional glycemic parameters in the discrimination of incident diabetes. Furthermore, subgroup analysis was performed according to the presence of central obesity. All statistical analyses were performed using SPSS version 24.0 (IBM Co., Armonk, NY, USA) and all figures were drawn in R version 3.2.5 (R Foundation for Statistical Computing, Vienna, Austria). All statistical tests were two-tailed and the significance level was set at $P<0.05$.

\section{RESULTS}

At baseline, a total of 7,512 subjects with non-diabetic state were enrolled in the present study. The cohort demographics were as follows: mean age, 52 years; mean BMI, $24.5 \mathrm{~kg} / \mathrm{m}^{2}$; and mean waist-to-hip ratio, 0.88 . Table 1 shows baseline anthropometric, 
Table 1. Baseline Characteristics

\begin{tabular}{|c|c|c|c|c|c|}
\hline Characteristic & All & NGT/normal HbAlc & NGT/high HbA1c & IGT/normal HbA1c & IGT/high HbA1c \\
\hline Number & 7,512 & 4,058 & 1,886 & 692 & 876 \\
\hline Urban area & $3,890(51.8)$ & $2,129(52.5)$ & $820(43.5)^{\mathrm{a}}$ & $469(67.8)^{\mathrm{a}, \mathrm{b}}$ & $472(53.9)^{\mathrm{a}, \mathrm{b}, \mathrm{c}}$ \\
\hline Age, yr & $51.6 \pm 8.7$ & $50.0 \pm 8.3$ & $53.6 \pm 8.8^{\mathrm{a}}$ & $51.5 \pm 9.0^{\mathrm{a}, \mathrm{b}}$ & $54.8 \pm 8.6^{\mathrm{a}, \mathrm{b}, \mathrm{c}}$ \\
\hline Men & $3,526(47.1)$ & $1,924(47.4)$ & $962(51.0)$ & $295(42.6)$ & $355(40.5)$ \\
\hline Body mass index, $\mathrm{kg} / \mathrm{m}^{2}$ & $24.5 \pm 3.1$ & $24.2 \pm 2.9$ & $24.9 \pm 3.1$ & $24.3 \pm 3.0$ & $25.6 \pm 3.2^{\mathrm{a}, \mathrm{b}, \mathrm{c}}$ \\
\hline \multicolumn{6}{|l|}{ Waist circumference, $\mathrm{cm}$} \\
\hline Men & $83.5 \pm 7.5$ & $82.6 \pm 7.2$ & $84.4 \pm 7.6^{\mathrm{a}}$ & $83.2 \pm 7.3$ & $86.2 \pm 7.5^{\mathrm{a}, \mathrm{b}, \mathrm{c}}$ \\
\hline Women & $81.4 \pm 9.5$ & $79.9 \pm 9.3$ & $84.0 \pm 9.4^{\mathrm{a}}$ & $79.3 \pm 9.2^{b}$ & $84.6 \pm 9.2^{\mathrm{a}, \mathrm{c}}$ \\
\hline \multicolumn{6}{|l|}{ Blood pressure, $\mathrm{mm} \mathrm{Hg}$} \\
\hline Systolic & $124(18)$ & $122(18)$ & $125(18)^{\mathrm{a}}$ & $125(19)^{\mathrm{a}}$ & $130(19)^{\mathrm{a}, \mathrm{b}, \mathrm{c}}$ \\
\hline Diastolic & $82(12)$ & $81(12)$ & $82(11)^{\mathrm{a}}$ & $81(12)$ & $84(11)^{a, b, c}$ \\
\hline \multicolumn{6}{|l|}{ Smoking status } \\
\hline Non-smoker & $4,405(58.6)$ & $2,418(60.4)$ & $1,002(53.7)$ & $440(63.9)$ & $545(63.4)$ \\
\hline Ex-smoker & $1,106(14.7)$ & $601(15.0)$ & $261(14.0)$ & $126(18.3)$ & $128(14.9)$ \\
\hline Current smoker & $1,899(25.3)$ & 985 (24.6) & $604(32.4)^{\mathrm{a}}$ & $123(17.9)^{\mathrm{a}, \mathrm{b}}$ & $187(21.7)^{b}$ \\
\hline \multicolumn{6}{|l|}{ Education status } \\
\hline High school or less & $6,437(86.4)$ & $3,439(85.4)$ & $1,631(87.4)$ & $599(86.8)$ & $768(88.5)$ \\
\hline College/university or more & $1,015(13.6)$ & $589(14.6)$ & $235(12.6)^{a}$ & $91(13.2)$ & $100(11.5)$ \\
\hline \multicolumn{6}{|l|}{ Monthly incomes } \\
\hline$<\$ 1,250 / \mathrm{mo}$ & 3,661 (49.6) & $1,854(46.5)$ & $1,034(56.0)^{\mathrm{a}}$ & $302(44.3)^{b}$ & $471(54.5)^{\mathrm{a}, \mathrm{c}}$ \\
\hline$\$ 1,250-3,300 / \mathrm{mo}$ & $3,159(42.8)$ & $1,820(45.6)$ & $687(37.2)$ & $317(46.5)$ & $335(38.8)$ \\
\hline$\geq \$ 3,300 / \mathrm{mo}$ & $560(7.6)$ & $315(7.9)$ & $125(6.8)$ & $62(9.1)$ & $58(6.7)$ \\
\hline Physical activity & $4,317(57.5)$ & $2,356(59.0)$ & $1,140(61.8)$ & $350(50.9)^{\mathrm{a}, \mathrm{b}}$ & $471(54.8)^{\mathrm{b}}$ \\
\hline Family history of diabetes & $762(10.1)$ & $383(9.4)$ & $186(9.9)$ & $94(13.6)$ & $99(11.3)$ \\
\hline \multicolumn{6}{|l|}{ Laboratory outcomes } \\
\hline $\mathrm{HbA1c}, \%$ & $5.5 \pm 0.3$ & $5.3 \pm 0.2$ & $5.9 \pm 0.2^{\mathrm{a}}$ & $5.4 \pm 0.2^{\mathrm{a}, \mathrm{b}}$ & $5.9 \pm 0.2^{\mathrm{a}, \mathrm{b}, \mathrm{c}}$ \\
\hline Fasting glucose, $\mathrm{mg} / \mathrm{dL}$ & $83(9)$ & $81(8)$ & $84(9)^{\mathrm{a}}$ & $85(9)^{\mathrm{a}}$ & $88(10)^{\mathrm{a}, \mathrm{b}, \mathrm{c}}$ \\
\hline 2-hour post-load glucose, mg/dL & $115(30)$ & $102(20)$ & $106(21)^{\mathrm{a}}$ & $158(15)^{\mathrm{a}, \mathrm{b}}$ & $161(16)^{\mathrm{a}, \mathrm{c}}$ \\
\hline Total cholesterol/HDL ratio & $4.4 \pm 1.1$ & $4.3(1.0)$ & $4.6 \pm 1.1^{\mathrm{a}}$ & $4.4 \pm 1.1^{b}$ & $4.8 \pm 1.2^{\mathrm{a}, \mathrm{b}, \mathrm{c}}$ \\
\hline HOMA-IR & $1.4(1.0-1.9)$ & $1.3(1.0-1.9)$ & $1.5(1.1-2.0)^{\mathrm{a}}$ & $1.4(1.0-1.9)^{\mathrm{b}}$ & $1.6(1.2-2.3)^{\mathrm{a}, \mathrm{b}, \mathrm{c}}$ \\
\hline Triglycerides, mg/dL & $134(99-186)$ & $125(94-170)$ & $144(108-199)^{\mathrm{a}}$ & $133(100-187)^{\mathrm{a}}$ & $163(120-231)^{\mathrm{a}, \mathrm{b}, \mathrm{c}}$ \\
\hline C-reactive protein, $\mathrm{mg} / \mathrm{L}$ & $0.14(0.06-0.24)$ & $0.12(0.05-0.21)$ & $0.15(0.07-0.26)^{\mathrm{a}}$ & $0.14(0.07-0.24)^{\mathrm{a}}$ & $0.17(0.09-0.30)^{\mathrm{a}}$ \\
\hline Creatinine clearance, $\mathrm{mL} / \mathrm{min}$ & $92.3 \pm 13.9$ & $93.7 \pm 13.6$ & $91.0 \pm 13.9^{\mathrm{a}}$ & $91.2 \pm 14.9^{\mathrm{a}}$ & $89.7 \pm 13.9^{\mathrm{a}}$ \\
\hline \multicolumn{6}{|l|}{ Cumulative incidence of diabetes } \\
\hline Cumulative incidence & $1,341(17.6)$ & $316(8.4)$ & $390(22.2)$ & $193(32.7)$ & $442(59.9)$ \\
\hline Incidence density, $/ 1,000$ person-years & 22.1 & 10.1 & 24.6 & 39.1 & 86 \\
\hline
\end{tabular}

Values are expressed as number (\%), mean \pm standard deviation, or median (interquartile range). Normal HbA1c, HbA1c $<5.7 \%$; high $\mathrm{HbA} 1 \mathrm{c}, 5.7 \%-$ $6.4 \%$; Physical activity, perform moderate-intensity ( $\geq 150$ minutes/week) or vigorous-intensity ( $\geq 75$ minutes/week) activity.

NGT, normal glucose tolerance (2-hour post-load glucose $<140 \mathrm{mg} / \mathrm{dL}$ ); HbAlc, glycated hemoglobin; IGT, impaired glucose tolerance (2-hour postload glucose 140-199 mg/dL); HDL, high density lipoprotein; HOMA-IR, homeostasis model assessment of insulin resistance.

${ }^{a} P$ values were calculated by analysis of variance (ANOVA) test (with Tukey's HSD as post hoc analysis) or chi-square test (with Bonferroni correction method) $P<0.05$ vs. NGT/normal HbA1c; ${ }^{b} P<0.05$ vs. NGT/high HbAlc; ${ }^{c} P<0.05$ vs. IGT/normal HbAlc. 
clinical, and laboratory characteristics of the study population according to each glycemic category. The IGT/high HbAlc group ( $n=876$ ) was older (mean age, 54.8 years), had higher blood pressure (mean SBP/DBP 130/84 mm Hg), higher HbA1c (mean $5.9 \%$ ), higher FPG (mean, $88 \mathrm{mg} / \mathrm{dL}$ ), 2hPG (mean, $161 \mathrm{mg} / \mathrm{dL}$ ), total cholesterol/HDL ratio (mean, 4.8), TG (median, $163 \mathrm{mg} / \mathrm{dL}$ ), and HOMA-IR levels (median, 1.6) than the other groups (all $P<0.05)$. Meanwhile, compared with isolated high HbAlc group (NGT/high HbAlc group; $n=1,886$ ), the isolated IGT group (IGT/ normal $\mathrm{HbA1c}$ group; $n=692$ ) was younger (mean age, 51.5 years vs. 53.6 years, $P<0.05$ ), had lower proportion of current smokers $(17.9 \%$ vs. $32.4 \%, P<0.05)$, higher monthly incomes ( $\geq 1,250$ dollars/month, $55.6 \%$ vs. $44 \%, P<0.05)$, less physical activity ( $50.9 \%$ vs. $61.8 \%, P<0.05)$, lower mean total cholesterol/HDL ratio (4.4 vs. 4.6, $P<0.05$ ), and median HOMA-IR levels (1.4 vs. 1.5, $P<0.05)$.

During the median follow-up period of 11.5 years (IQR, 6.0 to 11.8$), 1,341(17.6 \%)$ subjects were newly diagnosed with T2DM during follow-up, corresponding to incident density of 22.1 per 1,000 person-years. As expected, the cumulative incident density was the highest in the IGT/high HbA1c group ( 86.0 per 1,000 person-years) with a declining tendency in the NGT/normal HbAlc group (10.1 per 1,000 person-years) (Table 1).

\section{Risk for incident diabetes}

Both crude and adjusted HRs for incident diabetes were significantly highest in the IGT/high HbA1c group (crude model HR, 10.82; 95\% CI, 9.35 to 12.51) (adjusted model HR, 9.94; 95\% CI, 8.53 to 11.59) compared with the NGT/normal HbA1c group (reference group) (Table 2). In the subgroup comparison, the isolated IGT group was associated with higher risk (crude model HR, 4.41; 95\% CI, 3.67 to 5.28) (adjusted model HR, $4.29 ; 95 \%$ CI, 3.56 to 5.17 ) than the isolated high HbA1c group

Table 2. Incidental Risk of Diabetes According to Glycemic Status Stratified by the Presence of Central Obesity

\begin{tabular}{|c|c|c|}
\hline & Crude HR $(95 \% \mathrm{CI})$ & Adjusted HR $(95 \% \mathrm{CI})^{\mathrm{a}}$ \\
\hline \multicolumn{3}{|l|}{ Overall } \\
\hline NGT/normal HbAlc & 1 (reference) & 1 (reference) \\
\hline NGT/high HbA1c & $2.98(2.59-3.44)^{\mathrm{b}}$ & $2.79(2.40-3.26)^{\mathrm{b}}$ \\
\hline IGT/normal HbAlc & $4.41(3.67-5.28)^{\mathrm{b}, \mathrm{c}}$ & $4.29(3.56-5.17)^{\mathrm{b}, \mathrm{c}}$ \\
\hline IGT/high HbA1c & $10.82(9.35-12.51)^{\mathrm{b}, \mathrm{c}, \mathrm{d}}$ & $9.94(8.53-11.59)^{b, c, d}$ \\
\hline \multicolumn{3}{|l|}{ Central obesity - } \\
\hline NGT/normal HbAlc & 1 (reference) & 1 (reference) \\
\hline NGT/high HbA1c & $2.78(2.21-3.50)^{\mathrm{b}}$ & $2.70(2.13-3.43)^{\mathrm{b}}$ \\
\hline IGT/normal HbA1c & $4.60(3.58-5.93)^{b, c}$ & $4.52(3.49-5.87)^{\mathrm{b}, \mathrm{c}}$ \\
\hline IGT/high HbAlc & $10.61(8.51-13.22)^{b, c, d}$ & $9.65(7.65-12.18)^{b, c, d}$ \\
\hline \multicolumn{3}{|l|}{ Central obesity +} \\
\hline NGT/normal HbAlc & 1 (reference) & 1 (reference) \\
\hline NGT/high HbA1c & $2.99(2.45-3.64)^{b}$ & $2.82(2.30-3.46)^{b}$ \\
\hline IGT/normal HbA1c & $4.18(3.21-5.44)^{\mathrm{b}}$ & $3.95(3.01-5.18)^{\mathrm{b}}$ \\
\hline IGT/high HbAlc & $10.61(8.71-12.91)^{\mathrm{b}, c, d}$ & $9.98(8.13-12.26)^{b, c, d}$ \\
\hline
\end{tabular}

$\mathrm{HR}$, hazards ratio; CI, confidence interval; NGT, normal glucose tolerance; HbA1c, glycated hemoglobin; IGT, impaired glucose tolerance.

${ }^{a}$ The multivariable Cox proportional hazards regression model was adjusted for area, sex, age, estimated glomerular filtration, C-reactive protein, total-to-high density lipoprotein cholesterol ratio, triglycerides, systolic/diastolic blood pressure, and socioeconomic factors (education levels, monthly incomes, smoking, alcohol consumption, physical activity); ${ }^{b} P<0.05$ vs. NGT/normal HbA1c; ${ }^{c} P<0.05$ vs. NGT/high HbA1c; ${ }^{\mathrm{d}} P<0.05$ vs. IGT/normal HbA1c.

Table 3. The Predictive Performance of Different Glycemic Parameters Stratified by the Presence of Central Obesity for Type 2 Diabetes

\begin{tabular}{lllll}
\hline Covariates & Obesity & AUC (model 1) & AUC (model 2) & AUC (model 3) \\
\hline Age, sex, area & Non-obese & $0.69(0.67-0.71)$ & $0.74(0.72-0.76)^{\mathrm{a}}$ & $0.77(0.76-0.79)^{\mathrm{a}, \mathrm{b}}$ \\
& Obese & $0.66(0.63-0.69)$ & $0.75(0.73-0.78)^{\mathrm{a}}$ & $0.73(0.70-0.76)^{\mathrm{a}}$ \\
Age, sex, area+laboratory test+metabolic risk factors & Non-obese & $0.70(0.68-0.72)$ & $0.75(0.73-0.77)^{\mathrm{a}}$ & $0.78(0.76-0.80)^{\mathrm{a}, \mathrm{b}}$ \\
& Obese & $0.67(0.64-0.70)$ & $0.75(0.73-0.78)^{\mathrm{a}}$ & $0.73(0.71-0.76)^{\mathrm{a}}$ \\
Age, sex, area+laboratory test+metabolic risk & Non-obese & $0.71(0.69-0.73)$ & $0.75(0.74-0.77)^{\mathrm{a}}$ & $0.79(0.77-0.80)^{\mathrm{a}, \mathrm{b}}$ \\
factors+socioeconomic factors & Obese & $0.68(0.66-0.71)$ & $0.75(0.73-0.78)^{\mathrm{a}}$ & $0.75(0.71-0.77)^{\mathrm{a}}$ \\
\hline
\end{tabular}

Laboratory test: estimated glomerular filtration, C-reactive protein; Metabolic risk factors: the presence of dyslipidemia (triglyceride $\geq 2.8 \mathrm{mmol} / \mathrm{L}$ and/or high density lipoprotein [HDL] $<1 \mathrm{mmol} / \mathrm{L}$ [men] or HDL $<1.3 \mathrm{mmol} / \mathrm{L}$ [women] and/or taking lipid lowering drugs), hypertension (systolic blood pressure $\geq 140 \mathrm{~mm} \mathrm{Hg}$ and/or diastolic blood pressure $\geq 90 \mathrm{~mm} \mathrm{Hg}$ and/or taking anti-hypertensive drugs); Socioeconomic factors: education levels, monthly incomes, smoking, alcohol consumption, physical activity, and family history of diabetes. Presence of obesity: waist circumference $\geq 90 \mathrm{~cm}$ (men) or $\geq 85$ $\mathrm{cm}$ (women). Model 1, fasting plasma glucose (FPG); model 2, FPG+glycated hemoglobin levels; model 3, FPG+2-hour postprandial glucose.

AUC, area under the curve.

${ }^{\mathrm{a}} P<0.05$ vs. AUC (model 1$)$; ${ }^{\mathrm{b}} P<0.05$ vs. AUC (model 2). 

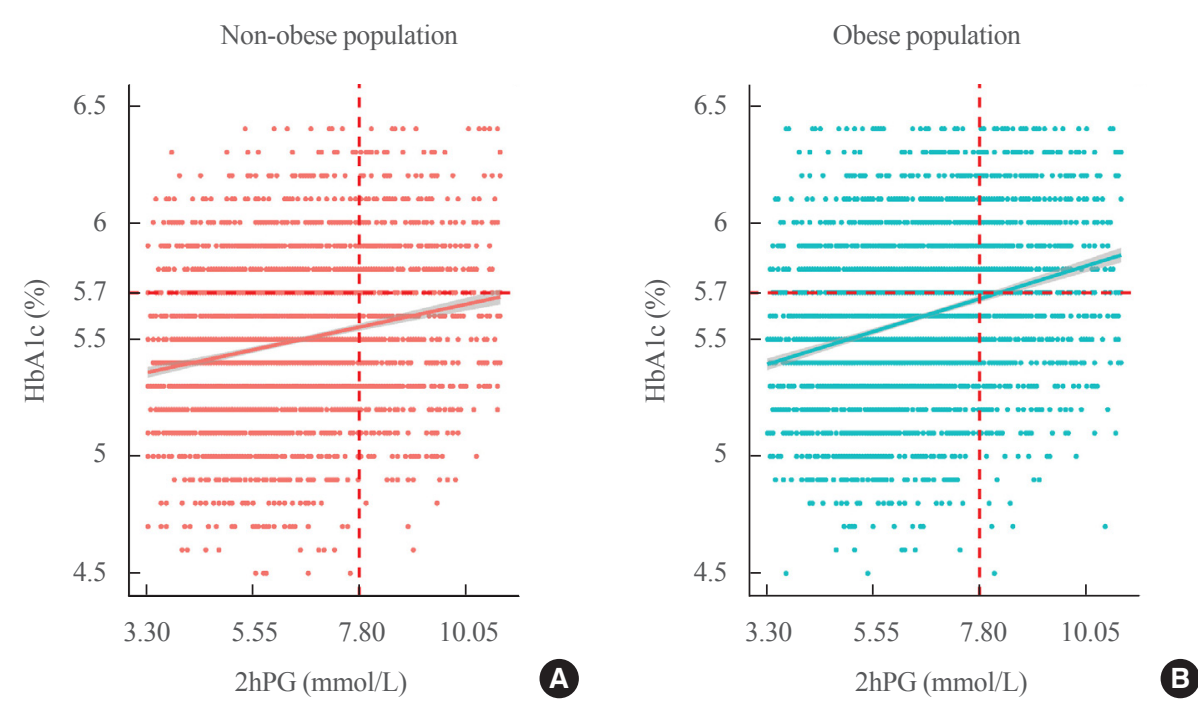

Fig. 1. The correlation between 2-hour postprandial glucose (2hPG; translated into mmol/L) and glycated hemoglobin (HbA1c; \%) stratified by the presence of central obesity. (A) Non-obese population. (B) Obese population. Central obesity, $\geq 90 \mathrm{~cm}$ (men) $\geq 85 \mathrm{~cm}$ (women).

(adjusted model HR, 2.79; 95\% CI, 2.40 to 3.26; both $P<0.05$ ) (Table 2). Otherwise, considering the presence of central obesity, the higher HR in isolated IGT group compared with the isolated high $\mathrm{HbAlc}$ group was lost among obese individuals (adjusted model HR, 3.95; 95\% CI, 3.01 to 5.18 in isolated IGT group vs. HR, 2.82; $95 \% \mathrm{CI}, 2.30$ to 3.46 in isolated high $\mathrm{HbA1c}$ group). When the obesity was defined by BMI cut-off value $\left(25 \mathrm{~kg} / \mathrm{m}^{2}\right)$, meanwhile, the presence of obesity does not affect the risk of incident diabetes between subgroup with isolated IGT and those with isolated high HbAlc (Supplemental Table S1). Kaplan-Meier curves demonstrated a clear separation of the curves for isolated IGT vs. isolated high HbAlc among centrally non-obese population (log-rank $P<0.001)$ but not among centrally obese population (Supplemental Fig. S1).

\section{The predictive power of models including each glycemic parameter for incident DM}

Whether or not the laboratory, metabolic, and socioeconomic confounding factors were included, high $\mathrm{HbA1c}$ level (model 2, C-index 0.753 ) or high $2 \mathrm{hPG}$ level (model 3, C-index 0.749) improved the prediction of incident T2DM compared with FPG test alone (model 1, C-index 0.684) (Table 3). Meanwhile, when we stratified subgroups according to the presence of central obesity, the higher predictive power of 'FPG+OGTT' model (model 3, C-index 0.785) compared with 'FPG+HbAlc' model (model 2, C-index 0.754) among centrally non-obese population was comparable to centrally obese population (C-index 0.754 vs. 0.749 ). The difference in discriminant ability between these subgroups according to the presence of obesity is similarly observed when BMI is applied as the criterion for obesity (C-index 0.75 for 'FPG+HbA1c' model vs. 0.77 for 'FPG+OGTT' model, $P=0.031$ ) (Supplemental Table S2).

\section{Correlation between glycemic parameters according to the} presence of central obesity

In the correlation analysis, the degree of correlation between $2 \mathrm{hPG}$ and $\mathrm{HbA1c}$ varied with the presence of central obesity. The correlation between $\mathrm{HbAlc}$ and $2 \mathrm{hPG}$ (converted to mmol/ L) was stronger in the subgroup with centrally obese population $(r=0.062)$ than in non-obese population $(r=0.041, P<0.001)$ (Fig. 1). A stronger association between $\mathrm{HbA} 1 \mathrm{c}$ and $2 \mathrm{hPG}$ in obese population was also observed when obesity was defined according to BMI criteria $\left(r=0.060\left[\geq 25 \mathrm{~kg} / \mathrm{m}^{2}\right]\right.$ vs. $r=0.037$ $\left.\left[<25 \mathrm{~kg} / \mathrm{m}^{2}\right] ; P<0.001\right)$. When an OGTT (2hPG) cutoff of 140 $\mathrm{mg} / \mathrm{dL}$ was adopted to detect prediabetes, the overall sensitivity, specificity, positive predictive value (PPV), and negative predictive value (NPV) of $\mathrm{HbAlc}$ criteria for prediabetes $(5.7 \%$ to $6.4 \%$ ) were $55.9 \%, 68.3 \%, 31.7 \%$, and $85.4 \%$, respectively. The sensitivity and PPV of HbA1c-criteria increased to $59.1 \%$ (vs. $49.4 \%$ ) and $35.1 \%$ (vs. $29.8 \%$ ) in obese individuals $(n=2,105)$ compared with non-obese individuals $(n=5,401)$ (Supplemental Table S3).

\section{DISCUSSION}

In this population-based cohort study, the different glycemic 
categories based on OGTT and HbAlc test showed that each glycemic parameter represent different clinical phenotypes. Individuals with high $2 \mathrm{hPG}$ had a higher risk of developing diabetes, regardless of the HbAlc level. In addition, 2hPG level had greater discriminatory capacity than HbA1c level. However, when diagnosed as prediabetes through $\mathrm{HbAlc}$ test, the number of subjects corresponding to actual IGT increased in obese population as the sensitivity of HbA1c test increases. As a result, the risk of incident diabetes and the predictive capacity between isolated IGT and isolated high HbAlc became comparable in obese population.

Different glycemic categories (measurements of FPG, 2hPG, and $\mathrm{HbA1c}$ ) probably reflect diverse pathophysiological features of glucose metabolism and the different clinical, socioeconomic characteristics. In this study population, the subgroup with isolated IGT had fewer risk factors associated with diabetes compared with those carrying isolated high $\mathrm{HbAlc}$ levels (5.7\% to $6.4 \%)$. Based on different clinical/anthropometric characteristics according to each diagnostic criteria, neither HbAlc test nor OGTT alone facilitated the detection of highrisk population and the accompanying risk factors to predict the risk of diabetes. Two tests (HbA1c and OGTT) can be used to measure different pathophysiological aspects of dysglycemia and a single positive result does not establish the accompanying risk factors and clinical phenotypes of diabetes.

The concordance between $2 \mathrm{hPG}$ and HbA1c levels was higher in obese population regardless of whether the BMI criterion or the WC criterion was adopted in our study. In addition, the sensitivity and PPV of HbAlc for prediabetes compared with OGTT also increased in obese individuals than in non-obese individuals. Increased oxidative stress in obesity [30] might explain elevated $\mathrm{HbA} 1 \mathrm{c}$ levels at a given glycemic level in obese population [24,31]. In the Insulin Resistance Atherosclerosis Study [32], the sensitivity of HbA1c criteria (5.7\% to $6.4 \%$ ) for prediabetes increased with increasing BMI $(67.8 \%$ in obese subjects [BMI $\geq 30 \mathrm{~kg} / \mathrm{m}^{2}$ ] vs. $19.9 \%$ in overweight subjects [BMI 25.0 to $\left.29.9 \mathrm{~kg} / \mathrm{m}^{2}\right]$ ), but this trend was not observed in IGT criteria (60.0\% in obese subjects vs. $58.1 \%$ in overweight subjects). In the Spanish non-diabetic community study, the prevalence of prediabetes was affected by BMI when the HbAlc criteria was applied but not in FPG criteria [33]. A pooled analysis of global surveillance of diabetes prevalence showed that the relationship between glucose-based and HbAlc-based prevalence of diabetes was partly related to participants' age and the presence of obesity, and the prevalence based on HbAlc increased with age, national income, and mean BMI [34].
Interestingly, among centrally obese population, the risk of incident T2DM in prediabetes defined by $\mathrm{HbA} 1 \mathrm{c}$ test alone became comparable to that of OGTT alone. In addition, the additional predictive performance of $\mathrm{HbAlc}$ and OGTT tests for diabetes was not different. Considering the general higher sensitivity of OGTT compared with HbAlc test in defining the highrisk population for diabetes, a higher accordance between HbA1c and 2hPG based on OGTT in obese subjects might increase the predictive power of HbAlc-based model compared with OGTT-based model. However, the findings do not warrant substitution of HbAlc for OGTT to determine the high risk for diabetes in obese population. Otherwise, it is necessary to recognize that the predictive power and the risk of diabetes based on $\mathrm{HbA1c}$ criteria may differ depending on the presence of central obesity. In interpreting the HbA1c test, an additional OGTT may be especially needed for risk analysis in non-obese subjects, even though the HbAlc is high (5.7\% to 6.4\%). However, if the obese subjects are considered at risk based on the $\mathrm{HbAlc}$ test, appropriate lifestyle modifications and drug therapy can be considered without additional confirmatory tests.

We acknowledge both the strengths and limitations of the study. This study has several strengths. A community-based longitudinal cohort study of middle-aged adults was conducted and the association between different glycemic parameters and incident diabetes was evaluated. In addition, information based on a large number of confounding factors including socioeconomic, anthropometric, and laboratory traditional risk factors were adjusted in the study. Glycemic parameters such as $\mathrm{HbA1c}$ test and OGTT were evaluated simultaneously and the performance of HbAlc was compared with $2 \mathrm{hPG}$ instead of FPG. Furthermore, based on this nationwide sample of urban/rural area population, subjects with anemia or hemoglobinopathies were excluded to validate the accuracy of HbAlc, which was affected by red cell metabolism.

However, the study findings from the Korean national cohort cannot be generalized to other races/ethnicities. We included subjects aged 40 to 69 years and excluded younger population. In addition, the longitudinal cohort observational study did not elucidate the causal relationship between different glycemic indices and incident diabetes. A further study is needed to evaluate the causal relationship.

In conclusion, the overall risk of future diabetes and the diagnostic performance of HbAlc test for identifying high risk subjects were inferior to OGTT, but became comparable among obese subjects as the sensitivity of HbAlc test increases. Depending on whether or not subjects are accompanied by central 
obesity, it may be helpful in determining whether an additional confirmatory test should be performed after the HbAlc test.

\section{CONFLICTS OF INTEREST}

No potential conflict of interest relevant to this article was reported.

\section{ACKNOWLEDGMENTS}

Data in this study were from the Korean Genome and Epidemiology Study (KoGES; 4851-302), National Research Institute of Health, Centers for Disease Control and Prevention, Ministry for Health and Welfare, Republic of Korea.

\section{AUTHOR CONTRIBUTIONS}

Conception or design: S.Y., J.J., H.K., J.H.B. Acquisition, analysis, or interpretation of data: S.Y., K.Y.K., S.K.K. Drafting the work or revising: J.J., J.R.H. Final approval of the manuscript: J.H.B

\section{ORCID}

Suji Yoo https://orcid.org/0000-0002-1769-9685

Jong Ha Baek https://orcid.org/0000-0002-1524-1742

\section{REFERENCES}

1. Ford ES, Zhao G, Li C. Pre-diabetes and the risk for cardiovascular disease: a systematic review of the evidence. J Am Coll Cardiol 2010;55:1310-7.

2. Huang Y, Cai X, Mai W, Li M, Hu Y. Association between prediabetes and risk of cardiovascular disease and all cause mortality: systematic review and meta-analysis. BMJ 2016; 355:i5953.

3. Dauriz M, Targher G, Temporelli PL, Lucci D, Gonzini L, Nicolosi GL, et al. Prognostic impact of diabetes and prediabetes on survival outcomes in patients with chronic heart failure: a post-hoc analysis of the GISSI-HF (Gruppo Italiano per lo Studio della Sopravvivenza nella Insufficienza Cardiaca-Heart Failure) Trial. J Am Heart Assoc 2017;6:e005156.

4. Kiviniemi AM, Lepojarvi ES, Tulppo MP, Piira OP, Kentta TV, Perkiomaki JS, et al. Prediabetes and risk for cardiac death among patients with coronary artery disease: the ARTEMIS study. Diabetes Care 2019;42:1319-25.
5. International Expert Committee. International Expert Committee report on the role of the $\mathrm{A} 1 \mathrm{C}$ assay in the diagnosis of diabetes. Diabetes Care 2009;32:1327-34.

6. American Diabetes Association. Diagnosis and classification of diabetes mellitus. Diabetes Care 2013;36(Suppl 1):S6774.

7. Qiao Q, Jousilahti P, Eriksson J, Tuomilehto J. Predictive properties of impaired glucose tolerance for cardiovascular risk are not explained by the development of overt diabetes during follow-up. Diabetes Care 2003;26:2910-4.

8. Warren B, Pankow JS, Matsushita K, Punjabi NM, Daya NR, Grams M, et al. Comparative prognostic performance of definitions of prediabetes: a prospective cohort analysis of the Atherosclerosis Risk in Communities (ARIC) study. Lancet Diabetes Endocrinol 2017;5:34-42.

9. Rosella LC, Lebenbaum M, Fitzpatrick T, Zuk A, Booth GL. Prevalence of prediabetes and undiagnosed diabetes in Canada (2007-2011) according to fasting plasma glucose and HbA1c screening criteria. Diabetes Care 2015;38:1299305.

10. Kim CH, Kim HK, Kim EH, Bae SJ, Choe J, Park JY. Risk of progression to diabetes from prediabetes defined by $\mathrm{HbA1c}$ or fasting plasma glucose criteria in Koreans. Diabetes Res Clin Pract 2016;118:105-11.

11. Hu Y, Liu W, Chen Y, Zhang M, Wang L, Zhou H, et al. Combined use of fasting plasma glucose and glycated hemoglobin A1c in the screening of diabetes and impaired glucose tolerance. Acta Diabetol 2010;47:231-6.

12. Fajans SS, Herman WH, Oral EA. Insufficient sensitivity of hemoglobin $\mathrm{A}\left({ }_{1} \mathrm{C}\right)$ determination in diagnosis or screening of early diabetic states. Metabolism 2011;60:86-91.

13. Engelgau MM, Thompson TJ, Herman WH, Boyle JP, Aubert RE, Kenny SJ, et al. Comparison of fasting and 2-hour glucose and HbA1c levels for diagnosing diabetes: diagnostic criteria and performance revisited. Diabetes Care 1997; 20:785-91.

14. Kramer CK, Araneta MR, Barrett-Connor E. A1C and diabetes diagnosis: the Rancho Bernardo Study. Diabetes Care 2010;33:101-3.

15. Meijnikman AS, De Block CE, Dirinck E, Verrijken A, Mertens I, Corthouts B, et al. Not performing an OGTT results in significant underdiagnosis of (pre)diabetes in a high risk adult Caucasian population. Int J Obes (Lond) 2017;41: 1615-20.

16. Hu X, Zhang Q, Zeng TS, Zhang JY, Min J, Tian SH, et al. Not performing an OGTT results in underdiagnosis, inade- 
quate risk assessment and probable cost increases of (pre)diabetes in Han Chinese over 40 years: a population-based prospective cohort study. Endocr Connect 2018;7:1507-17.

17. Sacks DB. A1C versus glucose testing: a comparison. Diabetes Care 2011;34:518-23.

18. Thewjitcharoen Y, Jones Elizabeth A, Butadej S, Nakasatien S, Chotwanvirat P, Wanothayaroj E, et al. Performance of $\mathrm{HbAlc}$ versus oral glucose tolerance test (OGTT) as a screening tool to diagnose dysglycemic status in high-risk Thai patients. BMC Endocr Disord 2019;19:23.

19. Vajravelu ME, Lee JM. Identifying prediabetes and type 2 diabetes in asymptomatic youth: should $\mathrm{HbA} 1 \mathrm{c}$ be used as a diagnostic approach? Curr Diab Rep 2018;18:43.

20. Yu EY, Wong CK, Ho SY, Wong SY, Lam CL. Can HbA1c replace OGTT for the diagnosis of diabetes mellitus among Chinese patients with impaired fasting glucose? Fam Pract 2015;32:631-8.

21. Unwin N, Howitt C, Rose AM, Samuels TA, Hennis AJ, Hambleton IR. Prevalence and phenotype of diabetes and prediabetes using fasting glucose vs $\mathrm{HbA} 1 \mathrm{c}$ in a Caribbean population. J Glob Health 2017;7:020407.

22. Iskandar S, Migahid A, Kamal D, Megahed O, DeFronzo RA, Zirie M, et al. Glycated hemoglobin versus oral glucose tolerance test in the identification of subjects with prediabetes in Qatari population. BMC Endocr Disord 2019;19:87.

23. Drzewoski J, Czupryniak L. Concordance between fasting and 2-h post-glucose challenge criteria for the diagnosis of diabetes mellitus and glucose intolerance in high risk individuals. Diabet Med 2001;18:29-31.

24. Li J, Ma H, Na L, Jiang S, Lv L, Li G, et al. Increased hemoglobin Alc threshold for prediabetes remarkably improving the agreement between A1c and oral glucose tolerance test criteria in obese population. J Clin Endocrinol Metab 2015;100:1997-2005.

25. He X, Mo Y, Ma X, Ying L, Zhu W, Wang Y, et al. Associations of body mass index with glycated albumin and glycated albumin/glycated hemoglobin A1c ratio in Chinese diabetic and non-diabetic populations. Clin Chim Acta 2018;
484:117-121.

26. Kim Y, Han BG; KoGES group. Cohort profile: the Korean Genome and Epidemiology Study (KoGES) Consortium. Int J Epidemiol 2017;46:e20.

27. Bonora E, Targher G, Alberiche M, Bonadonna RC, Saggiani $\mathrm{F}$, Zenere MB, et al. Homeostasis model assessment closely mirrors the glucose clamp technique in the assessment of insulin sensitivity: studies in subjects with various degrees of glucose tolerance and insulin sensitivity. Diabetes Care 2000;23:57-63.

28. Levey AS, Stevens LA, Schmid CH, Zhang YL, Castro AF 3rd, Feldman HI, et al. A new equation to estimate glomerular filtration rate. Ann Intern Med 2009;150:604-12.

29. Yoon YS, Oh SW. Optimal waist circumference cutoff values for the diagnosis of abdominal obesity in Korean adults. Endocrinol Metab (Seoul) 2014;29:418-26.

30. Marseglia L, Manti S, D’Angelo G, Nicotera A, Parisi E, Di Rosa G, et al. Oxidative stress in obesity: a critical component in human diseases. Int J Mol Sci 2014;16:378-400.

31. Sathiyapriya V, Selvaraj N, Nandeesha H, Bobby Z, Agrawal A, Sridhar MG, et al. Increased glycation of hemoglobin and plasma proteins in normotensive, non-diabetic obese Indian subjects: putative role of lipid peroxides. Clin Chem Lab Med 2007;45:996-9.

32. Lorenzo C, Wagenknecht LE, Hanley AJ, Rewers MJ, Karter AJ, Haffner SM. A1C between 5.7 and $6.4 \%$ as a marker for identifying pre-diabetes, insulin sensitivity and secretion, and cardiovascular risk factors: the Insulin Resistance Atherosclerosis Study (IRAS). Diabetes Care 2010;33:2104-9.

33. Rodriguez-Segade S, Rodriguez J, Camina F, Sanmartin-Portas L, Gerpe-Jamardo J, Pazos-Couselo M, et al. Prediabetes defined by $\mathrm{HbAlc}$ and by fasting glucose: differences in risk factors and prevalence. Acta Diabetol 2019;56:1023-30.

34. NCD Risk Factor Collaboration (NCD-RisC). Effects of diabetes definition on global surveillance of diabetes prevalence and diagnosis: a pooled analysis of 96 population-based studies with 331,288 participants. Lancet Diabetes Endocrinol 2015;3:624-37. 